\title{
Thermal and dynamic mechanical behavior of cellulose- and Oil Palm Empty Fruit Bunch (OPEFB)-filled polypropylene biocomposites.
}

\begin{abstract}
This paper presents a comparative study on the effect of cellulose and oil palm empty fruit bunch (OPEFB) on thermal degradation and dynamic mechanical properties of polypropylene (PP) biocomposite. Thermogravimetric analysis (TGA) of the biocomposite showed decrease in thermal stability and degradation temperature and increase in ash content. This was a result of lower thermal stability of the biofiller compared of that of the PP. However, an improvement was observed in the thermal properties of PP-cellulose biocomposite due to the dispersion and interfacial adhesion between the cellulose and PP. The glass transition temperatures ( $\mathrm{Tg}$ ) of the biocomposites were not significantly changed. The storage modulus $\left(\mathrm{E}^{\prime}\right)$ of the biocomposites was found to be higher than that of pure PP, because incorporation of biofiller increased the stiffness of the biocomposites. The decline in $\mathrm{E}^{\prime \prime}$ of the biocomposites at higher temperatures is associated with the increasing viscosity and chain mobility of matrix polymer.
\end{abstract}

Keyword: Biocomposite; Cellulose; Composites; Dynamicmechanical analysis (DMA); Polypropylene; Thermogravimetric analysis (TGA). 